\title{
Modular object-oriented methodology for the resolution of molten salt storage tanks for CSP plants
}

\author{
I. Rodríguez ${ }^{\mathrm{a}}$, C.D. Pérez-Segarra ${ }^{\mathrm{a}}$, O. Lehmkuhl ${ }^{\mathrm{a}, \mathrm{b}}$, A. Oliva ${ }^{\mathrm{a}, *}$ \\ ${ }^{a}$ Centre Tecnològic de Transferència de Calor, Universitat Politècnica de Catalunya,ETSEIAT, \\ Colom 11, 08222 Terrassa (Barcelona), Spain. \\ ${ }^{b}$ Termo Fluids, S.L. Avda. Jaquard, 97 1-E, 08222 Terrassa (Barcelona), Spain.
}

\begin{abstract}
Two-tank molten salt storages are the most widespread thermal energy storage technology within concentrated solar power plants. In spite of this, there are design aspects such as thermal losses control, optimisation of the storage or how these devices scale up with the increase in power capacity of the plant which still should be considered. In this sense, numerical modelling of these systems can be a powerful tool for reducing their cost. The present work aims at modelling molten salt tanks by proposing a parallel modular object-oriented methodology which considers the different elements of the storage (e.g. tank walls, insulation material, tank foundation, molten salt storage media, etc.) as independent systems. Each of these elements can be solved independently and using different levels of modelling (from global to fully three-dimensional models), while at the same time they are to linked each other through their boundary conditions. The mathematical models used, together with some illustrative examples of the application of the proposed methodology, are presented and discussed in detail.
\end{abstract}

Keywords: CFD\&HT, molten salt tanks, numerical modelling, multi-physics

\footnotetext{
*Tel: +3493739 8192; fax: +3493 7398101

Email address: cttcecttc.upc.edu (A. Oliva)
} 
model, TES

\section{Nomenclature}

$c_{p} \quad$ specific heat capacity, $J \mathrm{~kg}^{-1} \mathrm{~K}^{-1}$

$D \quad$ diameter, $m$

$e \quad$ internal energy, $\mathrm{J} \mathrm{kg}^{-1}$

$\boldsymbol{g}$ gravity vector, $m s^{-2}$

$\dot{g}_{k} \quad$ irradiation on surface $\mathrm{k}, W m^{-2}$

$H \quad$ height, $m$

$h \quad$ specific enthalpy, $\mathrm{J} \mathrm{kg}^{-1}$

I identity matrix

$\dot{m} \quad$ mass flow rate, $\mathrm{kg} \mathrm{s}^{-1}$

$\mathrm{Nu} \quad$ Nusselt number

n normal direction vector

$\operatorname{Pr} \quad$ Prandlt number, $\operatorname{Pr}=\frac{\mu c_{p}}{\lambda}$
$P r_{t} \quad$ Turbulent Prandlt number, $P r_{t}=$ $\frac{\mathrm{v}_{s g s}}{\kappa_{s g s}}$

$\dot{Q} \quad$ heat losses, $W$

$\dot{q} \quad$ specific heat flux, $W m^{-2}$

$R a \quad$ Rayleigh number, $R a=\frac{g \beta \Delta T H^{3}}{\nu \kappa}$

r $\quad$ radial direction, $m$

S $\quad$ surface area, $m^{2}$

$\mathcal{S}_{i j} \quad$ rate-of-strain, $s^{-1}$

${\overline{\mathcal{S}^{\prime}}}_{i j} \quad$ mean rate-of-strain fluctuations, $s^{-1}$

T temperature, $K$

t time, $s$

$\boldsymbol{u} \quad$ velocity vector, $m s^{-1}$

$\mathrm{z} \quad$ axial direction, $m$

Greek letters:

$\alpha \quad$ superficial heat transfer coefficient, $\mu \quad$ dynamic viscosity, $\mathrm{kg} \mathrm{m}^{-1} \mathrm{~s}^{-1}$ $W m^{-2} K^{-1}$

$\beta \quad$ thermal expansion coefficient, $K^{-1}$

$\checkmark \quad$ kinematic viscosity, $m^{2} s^{-1}$

$\Gamma \quad$ aspect ratio, $\Gamma=D / H$

$\xi \quad$ turbulent kinetic energy dissipation rate, $m^{2} s-3$

$\Delta \quad$ magnitude increment

$\rho \quad$ density, $\mathrm{kg} \mathrm{m}^{-3}$ 
$\varepsilon \quad$ thermal emissivity

$\eta \quad$ smallest turbulent scales of the flow, $\mathrm{m}$

$\theta \quad$ azimuthal direction, $m$

$\kappa \quad$ thermal diffusivity, $m^{2} s^{-1}$

$\lambda \quad$ thermal conductivity, $W m^{-1} K^{-1}$

Subscripts:

$b \quad$ bottom surface

c relative to passive cooling channels

conv convection

cv control volume

ext ambient conditions

$f s \quad$ molten salt free surface

$g \quad$ gas ullage

$i$ insulation

in inlet conditions $\sigma \quad$ Stefan-Boltzmann constant, $\sigma=$ $5.67 \times 10^{-8} W^{-2} K^{-4}$

$\mathcal{T}_{v} \quad$ stress tensor, $m^{2} s^{-2}$

$\Omega \quad$ volume, $m^{3}$

$\partial \Omega \quad$ surface which enclosed the volume

$\Omega, m^{2}$ ms molten salt

out outlet conditions

rad radiation

roof relative to container roof

s solar radiation

sgs subgrid scales

sky relative to sky radiation

t tank container

$v w \quad$ vertical wall

\section{Introduction}

Concentrated solar power plants (CSP) are a well-proven technology for providing a significant share of renewable electricity in the near future. Combined with thermal energy storage (TES) they can provide not only dispatchable electricity but also stability to the electricity network in case of high fraction of renewable production or intermittency due to cloudy weather conditions. Hence, 
thermal energy storage systems can be considered a key aspect for CSP plants due to their ability of extending solar power production beyond periods of no solar radiation reducing the mismatch between solar energy and demand. Examples of how to take advantage of this technology when operating solar plants can be found in $[1,2,3]$.

Considering the state-of-the-art in TES technologies, the two-tank system using molten salt is the most widespread configuration within CSP plants. Although the advantages of this technology against its competitors (PCM, solid, thermocline storages, etc.), there are design aspects which should still be considered such as avoid the salt freezing by controlling the heat losses, optimization of the storage (aspect ratio, design of the inlet ports, etc.) or determine how these devices scaleup with the power capacity of the plant, among others.

The design and optimisation of thermal storage tanks require a profound knowledge of the thermal and fluid dynamic phenomena involved. Due to the complex phenomena associated with the behaviour of these devices their optimised design is a challenge for researchers and engineers. In spite of these optimisation difficulties, designs are very often based on simple mathematical models (analytical methodologies based on global mass and energy balances or one-dimensional models), and expensive experimental trial-and-error analysis using scaled-down prototypes to provide the necessary information for these models (i.e. heat transfer coefficients in convection, pressure loss coefficients, mixing parameters, etc.).

The importance of global models relays on the fact that they are computational more efficient in terms of CPU time and thus, suitable for studying the long-term behaviour of these systems. However, their main drawback is the requirement of empirical-based information for fine-tuning the model, in order to 
predict accurately the different TES working conditions. Several global models have been reported in the literature, but most of them have been formulated for low-temperature applications (see for instance $[4,5,6,7,8]$ ). Recently, Gabbrielli and Zamparelli [9] presented a design procedure based on global models for selecting optimum parameters of molten salt tanks, considering also thermoeconomics issues.

On the other hand, detailed models based on the multi-dimensional resolution of the Navier-Stokes and energy equations should be capable of describing the thermal and fluid dynamic behaviour of storage tanks. In the last decades, detailed numerical simulations using computational fluid dynamics and heat transfer (CFD\&HT) codes have emerged as a powerful tool for the prediction of these systems. However, detailed numerical simulations demand large computational resources and, in spite of the use of parallel computers and efficient parallel algorithms, long-term simulations are still very costly. Yet, there are some works which take advantage of CFD\&HT simulations. The work carried out by Cònsul et al. [10] in which the storage tank stratification was analysed by using parallel computation techniques can be quoted. The transient natural convection inside a vertical cylinder with an imposed heat flux in the lateral walls was studied by Papanicolaou and Belessiotis [11] by using Reynolds averaged Navier-Stokes (RANS) equations with different turbulent models as closure. Later, the same authors modelled an underground storage with a k-E RANS model and studied its cool down process. Due to the lack of empirical information about the heat transfer coefficients in thermal storage tanks, CFD\&HT have also been used in order to obtain correlations capable of characterising the transient heat transfer process inside such equipment $[12,13,14]$. However, such correlations are in the range 
of Rayleigh numbers corresponding with low-temperature applications and small devices and thus, out-of-range to be used for molten salt TES.

As in the case of global models, most of the research carried out since now has been for low-temperature TES and using water as storage media. Among the different storage systems for high-temperature applications, one-tank thermocline storage (which is a dual system liquid-solid) has received more attention, and different multi-dimensional simulations (mostly two-dimensional) have been performed $[15,16,17]$. However, less consideration has received the most deployed storage technology (i.e. two-tank systems). In molten salt TES, heat transfer and fluid flow phenomena are very complex involving the radiative heat exchange between the free surface of the salt and the tank walls, the turbulent convections at very high Rayleigh numbers of the molten salt in the tank, heat losses from the multi-layered tank foundation, among others. All these phenomena pose a challenge for simulating such systems. One of the few CFD\&HT simulations carried out for these tanks was conducted by Schulte-Fischedick et al. [18], in which the cool down process of the Andasol tank was modelled by means of a k- $\varepsilon$ RANS model for two- and three-dimensional configurations. Due to the computational limitations, the authors pointed out that only for one of the simulations fully threedimensional computations were carried out.

Considering that the long-term behaviour of molten salt storage tanks can not be fully modelled by means of CFD\&HT computations due to the huge computational resources required, it is advisable to look for models which offer flexibility in order to combine correlations obtained from multi-dimensional simulations with global models for long-term behaviour. In this sense, the objective of this contribution is towards the development of a modular object-oriented simula- 
tion methodology for the design and optimisation of storage tanks for CSP plants. This methodology considers the different parts of the storage as independent models which also includes the coupling between global models and advanced computational fluid dynamic and heat transfer models mainly based on large-eddy simulation (LES) techniques. Parallelisation techniques, which allow the use of numerous processors in order to speed-up the simulations, are also considered. This is especially interesting if CFD\&HT techniques are used for detailed solving some elements of the storage (i.e. the molten salt fluid or the walls). This might require of parallelism techniques for the simulation to be feasible in reasonable time. The modular methodology, description of the different elements, the global resolution algorithm and some illustrative results obtained are presented in the following sections.

\section{Modular object-oriented methodology}

The implementation of the storage tank methodology has been made within the existing NEST platform [19] which allows the linking between different elements to perform a specific system or configuration. The main advantages of a modular object-oriented methodology are:

i Any basic element programmed in a general way can be used in a given configuration and re-used in other systems (e.g. tank walls and insulation materials can be modelled with the same object).

ii The elements which form a determined system interact only through their boundary conditions, being solved independently. This allows the direct substitution of a given model by another one (e.g. a one-dimensional ap- 
proach by a three-dimensional approach), while the rest of the elements which form the system remains unchanged.

iii Each element of a given system can be solved using a different parallelism paradigm without any need of re-writing any part of the code.

In the present implementation the storage tank of a CSP plant is considered as the sum of different parts, e.g. walls, tank foundation, molten salt fluid, etc., such as it is shown in figure 1. For each element of the storage more than one model approach is considered. For example, for modelling the convection in the molten salt different levels of modelling might be considered depending on the desired accuracy [14]. The use of a modular simulation allows that for the same element one-, two- or three-dimensional models can be used. At the same time, each element can receive a special treatment from the physical point of view (i.e. different hypothesis can be considered). This might be interesting if the influence of different hypothesis are to be considered. For instance, thermophysical properties can be assumed constant or variable with the temperature, density variations might be linearised with temperature (Boussinesq approximation) or a higher-order approximation can be applied, etc.

Each of these elements are capable of solving themselves given the appropriate boundary conditions, which can be obtained from the neighbouring elements once per outer iteration of the transient global algorithm. That is, at each time step, the governing equations of each object are solved taking the boundary conditions from the linked elements whereas, at the same instant, the outputs of each element are used as the boundary conditions for their neighbours. In this paper, the algorithm used for the resolution of the whole system of equations is a Gauss-Seidel like algorithm, in which iterations are carried out until convergence is attained. Then, 
after updating the variables, the algorithm goes to the next time step. For more details about the general algorithm the reader is referred to [19].

\section{Mathematical model}

As aforementioned, the TES is considered to be formed for different elements (see figure 2), which interact each other through their boundary conditions. Thus, proper mathematical formulation for each of them should be provided in order to be solved within the NEST platform. A scheme of the different elements of the model and its boundary conditions is given in figure 1 . The mathematical model considers:

- Transient behaviour of the whole system

- The gas ullage

- Convection and radiation effects between the molten salt free surface and its surroundings

- Tank walls and insulation

- Different material in the foundation and the passive cooling of the foundation

The complete set of objects (elements) considered for the current implementation is given in Table 1. In addition, a brief mathematical description of some of these models is given hereafter. 


\begin{tabular}{ll}
\hline Object/Model & Description \\
\hline Molten salt model & Global model for the energy balance of the molten salt \\
& fluid \\
\hline Molten salt CFD\&HT & Detailed three-dimensional model for the resolution \\
& of the fluid flow and heat transfer of the molten salt \\
& fluid considering LES turbulence modelling \\
\hline Gas ullage & Global model for the energy balance of the gas be- \\
& tween the molten salt and the top tank walls (see fig. \\
& 1) \\
\hline Molten salt free surface & $\begin{array}{l}\text { Global model for considering the free-surface of the } \\
\text { molten salt }\end{array}$ \\
\hline Wall & Single material layer with the one-dimensional heat \\
& conduction through a tank wall (i.e. container, insula- \\
tion material, etc.)
\end{tabular}

Table 1: Elements considered in the storage tank model 


\subsection{Molten salt global model}

The molten salt fluid can be evaluated by means of global balances in which the transient evolution of the temperature is considered, together with the interaction with the other elements through the boundary conditions (see figure 1 for details). The mass and energy balances for the molten salt region can be written as,

$$
\begin{gathered}
\frac{d}{d t} \int_{\Omega_{m s}} \rho_{m s} d \Omega+\dot{m}_{m s}^{\text {out }}-\dot{m}_{m s}^{i n}=0 \\
\frac{d}{d t} \int_{\Omega_{m s}} \rho_{m s} e_{m s} d \Omega+(\dot{m} e)_{m s}^{o u t}-(\dot{m} e)_{m s}^{i n} \approx-\int_{\partial \Omega_{m s}} \dot{\boldsymbol{q}} \cdot \boldsymbol{n} d S-\int_{\partial \Omega_{m s}} p \boldsymbol{u} \cdot \boldsymbol{n} d S
\end{gathered}
$$

In the above equation kinetic energy variation and viscous dissipation $\left(\mathcal{T}_{v}: \nabla \boldsymbol{u}\right)$ have been considered negligible, the change in internal energy is $d e=c_{p} d T$, and the heat flux integral can be interpreted as the sum of all the heat losses through the tank foundations $\dot{Q}_{b}$, the vertical walls $\dot{Q}_{v w}$, and through the molten salt free surface $\dot{Q}_{f s}$, i.e.

$$
-\int_{\partial \Omega_{m s}} \dot{\boldsymbol{q}} \cdot \boldsymbol{n} d S=-\dot{Q}_{b}-\dot{Q}_{v w}-\dot{Q}_{f s}
$$

where, 


$$
\begin{aligned}
\dot{Q}_{b} & =\int_{\partial \Omega_{b}} \alpha_{m s}^{b}\left(\bar{T}_{m s}-T_{b}\right) d S \\
\dot{Q}_{v w} & =\int_{\partial \Omega_{v w}} \alpha_{m s}^{\nu w}\left(\bar{T}_{m s}-T_{v w}\right) d S \\
\dot{Q}_{f s} & =\int_{\partial \Omega_{f s}}\left[\alpha_{m s}^{f s}\left(\bar{T}_{f s}-\bar{T}_{g}\right)+\varepsilon_{m s} \sigma \bar{T}_{f s}^{4}-\varepsilon_{m s} \dot{g}_{m s}\right] d S
\end{aligned}
$$

Correlations for the local heat transfer coefficients at the vertical and bottom walls are taken from [20].

\subsection{CFD\&HT molten salt object}

The objectives for using a CFD\&HT object for modelling the salt inside the storage are two-fold: i) such modelling would shed some light into the complex physics present, specially during the cool down process in which there is risk of salt freezing and, ii) there are not specific correlations for the heat transfer inside tanks, thus results of such modelling would be used for proposing new correlations to be used in the global model for the salt convective process. The CFD\&HT molten salt object calls TermoFluids CFD\&HT code [21] which is an object-oriented parallel and unstructured CFD\&HT code for the resolution of industrial flows. In this object, the three-dimensional Navier-Stokes equations are spatially filtered. Therefore, some level of modelisation for the filtered non-linear convective terms is required. This approach is known as large-eddy simulation (LES) of the turbulent flow. In LES, all temporal scales of the flow together with the largest spatial scales are solved, and only the small scales of the flow are modelled by means of a sub-grid scale model (SGS). The main reason for performing LES computations, rather than the less computational resource demand- 
ing Reynolds averaged Navier-Stokes models (RANS), is because in RANS the equations are filtered in space and time and thus, they are not properly formulated for describing the complex transient and three-dimensional turbulent phenomena here under study.

The discretised continuity, momentum and energy filtered equations, assuming constant thermophysical properties and negligible viscous dissipation effects in the energy equation read,

$$
\begin{aligned}
\boldsymbol{M} \overline{\boldsymbol{u}} & =\mathbf{0} \\
\Omega \frac{\partial \overline{\boldsymbol{u}}}{\partial t}+\mathrm{C}(\overline{\boldsymbol{u}}) \overline{\boldsymbol{u}}+\mathrm{v} \mathcal{D} \overline{\boldsymbol{u}}+\rho^{-1} \Omega \mathrm{G} \overline{\boldsymbol{p}}+\boldsymbol{f} & =\mathrm{C}(\overline{\boldsymbol{u}}) \overline{\boldsymbol{u}}-\overline{\mathrm{C}(\boldsymbol{u}) \boldsymbol{u}} \\
& \approx-\mathcal{M} \mathcal{T} \\
\Omega \frac{\partial \overline{\boldsymbol{T}}}{\partial t}+\mathrm{C}(\overline{\boldsymbol{u}}) \overline{\boldsymbol{T}}+\kappa \mathcal{D} \overline{\boldsymbol{T}} & =\mathrm{C}(\overline{\boldsymbol{u}}) \overline{\boldsymbol{T}}-\overline{\mathrm{C}(\boldsymbol{u}) \boldsymbol{T}} \\
& \approx-\mathcal{M} \mathcal{T}_{\mathcal{T}}
\end{aligned}
$$

where $\overline{\boldsymbol{u}} \in \mathbb{R}^{3 m}, \overline{\boldsymbol{p}} \in \mathbb{R}^{m}$ and $\overline{\boldsymbol{T}} \in \mathbb{R}^{m}$ are the filtered velocity vector, pressure and temperature, respectively (here $\mathrm{m}$ applies for the total number of control volumes (CV) of the discretised domain). $\Omega \in \mathbb{R}^{3 m}$ is a matrix with the cell control volumes. $f$ are the body forces, $f=\beta\left(T-T_{r e f}\right) g$. Convective and diffusive operators are given by $\mathrm{C}(\overline{\boldsymbol{u}})=(\overline{\boldsymbol{u}} \cdot \nabla) \in \mathbb{R}^{3 m \times 3 m}, \mathcal{D}=-\nabla^{2} \in \mathbb{R}^{3 m \times 3 m}$ respectively. Gradient and divergence (of a vector) operators are given by $G=\nabla \in \mathbb{R}^{3 m \times m}$ and $\boldsymbol{M}=\boldsymbol{\nabla} \cdot \in \mathbb{R}^{m \times 3 m}$ respectively.

The last term in equations 8 and 9 indicate some modelisation of the filtered non-linear convective term. $\mathcal{M}$ represents the divergence operator of a tensor, and $\mathcal{T}$ is the sub-grid scale (SGS) stress tensor, which is defined as [22],

$$
\mathcal{T}=-2 v_{s g s} \mathcal{S}_{i j}+(\mathcal{T}: \boldsymbol{I}) \boldsymbol{I} / 3
$$


where $\mathcal{S}_{i j}=\frac{1}{2}\left[\mathrm{G}(\overline{\boldsymbol{u}})+\mathrm{G}^{*}(\overline{\boldsymbol{u}})\right]$, and $\mathrm{G}^{*}$ is the transpose of the gradient operator. $\mathcal{T}_{\mathcal{T}}$ term is evaluated as in $\mathcal{T}$ term, but $v_{s g s}$ is substituted by $v_{s g s} / P r_{t}$, where $\mathrm{Pr}_{t}$ is the turbulent Prandlt (0.4 in this paper). To close the formulation, a suitable expression for the subgrid-scale (SGS) viscosity, $v_{s g s}$, must be introduced. In order to use the most adequate model for the natural convection phenomena at high Rayleigh numbers present in molten salt tanks, different SGS models have been investigated: i) the dynamic eddy viscosity model (DEV) [23], ii) the walladapting local-eddy viscosity (WALE) [24], iii) the WALE model within a variational multiscale framework (VMS-WALE) [25] and iv) the QR-model based on the invariants of the rate-of-strain tensor [26]. In the next section, a comparison of the performance of the different models is given.

The governing equations used in TermoFluids CFD\&HT code are discretised on a collocated unstructured grid arrangement by means of second-order conservative schemes [27], i.e. they preserve the kinetic energy equation which ensures stability and conservation of the kinetic-energy balance even at high Reynolds numbers and with coarse grids.

In the context of the large-eddy simulation of turbulent flows, the time advancement algorithm should be capable of solving all relevant temporal scales while, at the same time, it should be kept within the stability domain. Different temporal schemes have been proposed in the literature to deal with time marching algorithm for turbulent flows (see for instance $[28,29,30]$ ). In this work, a two-step linear explicit scheme on a fractional-step method proposed by Trias \& Lehmkuhl [31] is used. Its main advantage relies on its capacity of dynamically adapt the time step to the maximum possible value while at the same time it is kept within the stability limits. This strategy reduces the computational time required 
without lost of accuracy. The method has been successfully tested in different flows in $[32,33,34]$.

\subsection{Tank walls and insulation}

Any solid wall, including the container and the insulation material, can be evaluated by an object which implements a transient heat balance as,

$$
\rho_{k} c_{p k} \frac{\partial T_{k}}{\partial t}=\nabla \cdot\left(\lambda_{k} \nabla T_{k}\right)
$$

The above equation can be used for evaluating each $k_{t h}$ wall depending on the appropriate boundary conditions at which the object is linked. For instance, in the case of the tank container which is bounded by the molten salt and the insulation material, local boundary conditions would read,

- for the molten salt tank walls boundary, $\alpha_{m s}\left(\bar{T}_{m s}-T_{t}\right)=-\lambda_{t} \nabla T_{t} \cdot \boldsymbol{n}$

- for the internal tank walls/insulation, $-\lambda_{t} \nabla T_{t} \cdot \boldsymbol{n}=-\lambda_{k} \nabla T_{k} \cdot \boldsymbol{n}$

In a similar way, the most external layers would be bounded by,

- for the internal surface interfaces, $-\lambda_{k-1} \nabla T_{k-1} \cdot \boldsymbol{n}=-\lambda_{k} \nabla T_{k} \cdot \boldsymbol{n}$

- the external boundary condition, $-\lambda_{k} \nabla T_{k} \cdot \boldsymbol{n}=\alpha_{\text {ext }}\left(T_{k}-T_{\text {ext }}\right)+\varepsilon_{k} \sigma\left(T_{k}^{4}-\right.$ $\left.T_{s k y}^{4}\right)-\dot{q}_{s}$

\subsection{Tank foundation object}

The foundation of molten salt storage tanks is composed of different layers including, among other elements, a foam-glass insulation layer, a passive cooling system and a reinforced concrete layer which can stand only up to certain temperature (about $90^{\circ} \mathrm{C}$ ). In contrast with the object which evaluates the container solid 
walls and the insulation material, this object is a multi-layer module where each element is represented by an energy balance equation as,

$$
\rho_{i} c_{p i} \frac{\partial T_{i}}{\partial t}=\nabla \cdot\left(\lambda_{i} \nabla T_{i}\right)-\dot{q}_{v, i} \quad i=1,2, \ldots, N
$$

In general, $\dot{q}_{v, i}=0$ except in the layer with passive cooling. Depending on the layer, different boundary conditions are set:

- For the top-most layer, $-\lambda_{i} \nabla T_{i} \cdot \boldsymbol{n}=-\lambda_{t} \nabla T_{t} \cdot \boldsymbol{n}$

- For the internal interfaces, $-\lambda_{i-1} \nabla T_{i-1} \cdot \boldsymbol{n}=-\lambda_{i} \nabla T_{i} \cdot \boldsymbol{n}$

- For the bottom-most layer, $T=T_{\text {soil }}$

The layer with passive cooling receives an especial attention, and due to the natural circulation within the channels, balances of mass, momentum and energy to be solved are,

$$
\begin{aligned}
\frac{\partial}{\partial t} \int_{\Omega} \rho_{c} d \Omega+\dot{m}_{c}^{\text {out }}-\dot{m}_{c}^{\text {in }} & =0 \\
\frac{\partial}{\partial t} \int_{\Omega} \rho_{c} \boldsymbol{u}_{c} d \Omega+(\dot{m} \boldsymbol{u})_{c}^{\text {out }}-(\dot{m} \boldsymbol{u})_{c}^{i n} & =-\int_{\partial \Omega} \boldsymbol{n} \cdot \mathcal{T}_{v} d S+\int_{\Omega} \boldsymbol{g} \rho_{c} d \Omega \\
\frac{\partial}{\partial t} \int_{\Omega} \rho_{c} e_{c} d \Omega+(\dot{m} h)_{c}^{\text {out }}-(\dot{m} h)_{c}^{\text {in }} & \approx \int_{\partial \Omega} \alpha_{c}\left(T_{k}-T_{c}\right) d S
\end{aligned}
$$

The above set of equations should be solved with proper boundary conditions. For the inlet boundary, temperature of air is fixed to the ambient temperature, i.e. $T=T_{\text {ext }}$, while pressure should be set as $p=p_{\text {ext }}-\rho_{\text {ext }}|\boldsymbol{g}| H_{\text {in }}$. At the outlet, pressure is imposed as $p=p_{\text {ext }}-\rho_{\text {ext }}|\boldsymbol{g}| H_{\text {out }}$. For the energy equation, the 
channel surfaces are directly linked within the multi-layer object which closes the balance.

\subsection{Gas ullage object}

The region between the molten salt free surface and the top wall of the container should also be considered in the global methodology, as it contributes to the heat losses. The balance for the gas contained in this zone reads,

$$
\begin{aligned}
\frac{d}{d t} \int_{\Omega_{g}} \rho_{g} d \Omega+\dot{m}_{g}^{\text {out }}-\dot{m}_{g}^{\text {in }} & =0 \\
\frac{d}{d t} \int_{\Omega_{g}} \rho_{g} e_{g} d \Omega+(\dot{m} e)_{g}^{\text {out }}-(\dot{m} e)_{g}^{i n} & \approx \int_{\partial \Omega_{v w}} \alpha_{g}^{f s}\left(\bar{T}_{f s}-\bar{T}_{g}\right) d S \\
& -\int_{\partial \Omega_{v w}+\partial \Omega_{\text {roof }}} \alpha_{g}^{t}\left(\bar{T}_{g}-T_{t}\right) d S \\
& -\int_{\partial \Omega_{g}} p \boldsymbol{u} \cdot \boldsymbol{n} d S
\end{aligned}
$$

Similar to the other objects, the gas ullage is linked through its boundary conditions with the molten salt free-surface and the container walls.

\section{Results}

\subsection{Validation of the CFD\&HT model}

Although the code used for modelling the CFD\&HT molten salt object described in previous section has been widely verified and validated using direct numerical simulations results and experimental data from the scientific research bibliography (e.g. $[35,36,37,33])$, it is important to select the most appropriate 
LES model capable of describing the heat transfer and fluid flow phenomena inside the tank. To do this, the wall confined natural convection flow in a cylindrical enclosure, known as Rayleigh-Bénard problem, is used. This case is characterised by a highly fluctuating temperature field at the bulk, which is nearly uniform in the time average, and high temperature gradients near the walls. Due to the temperature difference, large thermal plumes transport the thermal and kinetic energy between the walls (see figure 5). The flow configuration observed in a turbulent Rayleigh-Benard problem is somewhat similar to that developed in the storage tank, but at the same time it is a canonical case suitable for testing and selecting the most appropriate LES model. Thus, it would be expected that if a LES model performs well for the Rayleigh-Bénard case, it will also perform well for the molten salt tank. Numerical solutions of the different LES models are tested against the direct numerical solution (DNS) for a Rayleigh number $R a=2 \times 10^{9}$ [38]. As in DNS, all relevant spatial and temporal scales of the flow are solved, it is expected that, the better the performance of the LES model, the better agreement with the DNS solution.

The numerical computations are carried out with different grids for the case defined by $R a=2 \times 10^{9}, \operatorname{Pr}=0.7$ and aspect ratio $\Gamma=0.5$. Three different grids have been considered: $\mathrm{m} 1 \equiv 4321 \times 32$ planes (i.e. 32 planes in the azimuthal direction with 4321 control volumes per plane, for a total of 138271 control volumes); $\mathrm{m} 2 \equiv 8756 \times 32$ planes and $\mathrm{m} 3 \equiv 8756 \times 64$ planes. In table 2 the results for the average, minimum and maximum Nusselt numbers are given. For reference, the value measured experimentally by Niemela et al. [39] is also given in the table. As can be seen, the DNS average Nusselt number agrees well with the experimental measurements, with a relative error of $0.56 \%$ and, in general, LES 
computations predict this quantity with high accuracy. A close inspection of the average temperature and velocity profiles at the centre of the cavity is depicted in figure 6 for the coarse and finest meshes (i.e. $\mathrm{m} 1$ and $\mathrm{m} 3$ meshes). As can be seen, small differences are observed in the temperature distribution for all models and all grids. However, larger differences are obtained in the velocity field with the coarse grid. As the grid is refined, these differences are washed out and all models perform well.

In general, DEV and QR models perform better. This can be attributed in part to the characteristics of this flow, which behaves similar to homogeneous turbulence, specially at the core of the cavity. In addition, the use of a conservative formulation, which preserves the kinetic-energy balance even on a coarse grid [27], together with the integration time used which ensures converged temporal statistics, also contribute to enhance the performance of the SGS models. Taking into account that the objective is to use a mesh as coarse as possible to solve accurately the flow inside the tank and, at the same time to reduce the CPU time as much as possible, then the QR model is the best alternative, as it yielded the better results even with the coarsest grid. Thus, LES computations for the molten salt CFD\&HT object are carried out with the QR model.

\subsection{Illustrative results from the global balance model}

As an illustrative case, the transient thermal simulation of the molten salt storage tank of Andasol plant is here considered. The geometry data for this particular case are taken from $[40,18]$. In this case, cooling-down processes of the hot $\left(T_{m s}=384^{\circ} \mathrm{C}\right)$ and cold $\left(T_{m s}=290^{\circ} \mathrm{C}\right)$ storage tanks are considered. In addition, as boundary conditions of the whole tank ambient temperature and soil temperatures are set as $T_{\text {ext }}=25^{\circ} \mathrm{C} ; T_{\text {soil }}=12^{\circ} \mathrm{C}$, respectively. 


\begin{tabular}{|c|c|c|c|c|c|c|c|}
\hline Grid & Model & $\overline{N u}$ & $\varepsilon[\%]$ & $N u_{\max }$ & $\varepsilon[\%]$ & $N u_{\text {min }}$ & $\varepsilon[\%]$ \\
\hline & $\exp [39]$ & 85.45 & & & & & \\
\hline$m_{D N S}$ & DNS & 84.97 & - & 100.14 & - & 44.78 & - \\
\hline \multirow{5}{*}{$4321 \times 32$} & no model & 85.73 & 0.89 & 112.39 & 12.2 & 33.15 & 25.9 \\
\hline & WALE & 82.60 & 2.78 & 106.69 & 6.5 & 36.18 & 19.2 \\
\hline & $\mathrm{DEV}$ & 81.84 & 3.7 & 104.64 & 4.5 & 35.25 & 21.2 \\
\hline & QR & 83.75 & 1.43 & 109.12 & 8.9 & 31.84 & 28.8 \\
\hline & VMS-WALE & 85.14 & 0.2 & 111.11 & 10.9 & 34.97 & 21.9 \\
\hline \multirow{5}{*}{$8756 \times 32$} & no model & 84.61 & 0.42 & 116.17 & 16.0 & 36.37 & 18.8 \\
\hline & WALE & 82.02 & 3.5 & 110.51 & 10.3 & 36.75 & 17.9 \\
\hline & $\mathrm{DEV}$ & 81.84 & 3.7 & 104.65 & 4.5 & 35.79 & 20.1 \\
\hline & QR & 82.57 & 2.8 & 110.19 & 10.03 & 32.99 & 26.3 \\
\hline & VMS-WALE & 84.27 & 0.82 & 104.93 & 4.7 & 35.15 & 21.5 \\
\hline \multirow{5}{*}{$8756 \times 64$} & no model & 87.3 & 2.7 & 104.04 & 3.9 & 42.92 & 4.1 \\
\hline & WALE & 86.97 & 2.3 & 102.44 & 2.3 & 42.45 & 5.2 \\
\hline & $\mathrm{DEV}$ & 84.29 & 0.8 & 100.4 & 0.26 & 43.08 & 3.7 \\
\hline & QR & 84.48 & 0.57 & 100.29 & 0.15 & 41.19 & 8.01 \\
\hline & VMS-WALE & 86.5 & 1.8 & 101.98 & 1.8 & 43.13 & 3.6 \\
\hline
\end{tabular}

Table 2: Comparison of the average, maximum and minimum Nusselt numbers between LES and DNS results for the different grids solved. 
Here, the working fluid is the solar salt $\left(60 \% \mathrm{NaNO}_{3}-40 \% \mathrm{KNO}_{3}\right)$, the tank container is of steel A516gr70 and, as insulation material for the lateral and roof walls, Spintex342G-100 is used. A sketch of the walls and foundation layers adapted from [41] is depicted in figure 3. The detailed information about the thermo-physical properties of these materials are given in table 3.

Other details about geometry used are given hereafter:

- Storage tanks internal diameter and height $\mathrm{D}=38.5 \mathrm{~m} ; \mathrm{H}=14 \mathrm{~m}$ (vertical walls).

- The vertical wall has different thicknesses as a function the tank height (see figure 3). Thus, $\delta=0.0185 m$ if $3 \Delta z \leq z<4 \Delta z ; \delta=0.0115 m$ if $4 \Delta z \leq z<$ $5 \Delta z ; \delta=0.010 m$ if $5 \Delta z \leq z<6 \Delta z$, being $\Delta z=2.333 m$.

- Insulation thickness for the hot tank is set to $\delta=0.4 m$ and for the cold one $\delta=0.3 m$.

- Similar to vertical wall, bottom wall also considers different thicknesses as a function of the distance from the tank centre, $\delta=0.008 m$ for $0 \leq r<18.6 m$; $\delta=0.015 m 18.6 m \leq r<19.2 m$

- Foundation thicknesses: slip plate, $\delta=0.006 m$; dry sand, $\delta=0.006 m$; foam-glass, $\delta=0.420 \mathrm{~m}$; hard fire-brick, $\delta=0.060 \mathrm{~m}$; insulating fire-brick, $\delta=0.360 m$; heavy weight concrete, $\delta=0.450 m$; soil, $\delta=9 m$.

For the resolution of the cooling-down process of both hot and cold molten salt tanks the fluid has been solved using the global model coupled to the composite wall. It has to be mentioned, that the solid walls and the insulation materials are discretised considering the variation of the temperature along the axial plane of 
these solid materials. In addition, the free surface of the molten salt fluid has been linked to the gas ullage object, which at the same time this element is linked to the roof of the tank (different layers of the wall object).

Illustrative results of the heat losses through the different walls for both, hot and cold, tanks are depicted in figure 4. These results are comparable to that obtained for Schulte-Fischedick et al. [18] for a similar situation. However, although the results exhibit the same trend to that of the literature, there are differences in the global values obtained. For instance, total losses through the tank walls for the hot tank fully loaded yielded $194 \mathrm{~kW}$ against the $259 \mathrm{~kW}$ obtained by SchulteFischedick et al. [18]. Main differences are obtained in the top walls, but might be due not only to the differences in the models used, but also in the geometry of the tank. In this paper, all details of the real geometry are considered (e.g. variable wall thicknesses in both lateral and bottom walls), whereas in the simulations presented by Schulte-Fischedick et al. [18] a simplified geometry seems to be used. Another issue to take into account is the definition of the boundary conditions for the case, which are not exactly the same as those considered in the literature (they are not fully specified in the referred article).

\subsection{Towards the CFD\&HT modelling of the molten salt tank}

Simulations using the CFD\&HT object are also carried out. In this case, due to the complex phenomena present but without loss of generality, the dimensions of the tank are scaled-down to run these simulations with a reasonable CPU time consumption. The objectives of these simulations are two fold: i) first, to test the coupling of the CFD\&HT object with the other elements and, ii) to gain insight into the cooling process of the tank. In these simulations, the cooling-down

process of the cold tank $\left(T_{m s}=290^{\circ} \mathrm{C}\right)$ fully loaded is considered. In the scaling 


\section{Molten salt}

$$
\begin{array}{ll}
\rho & 2090-0.636 \hat{T} \\
c_{p} & 1443+0.172 \hat{T} \\
\mu & 2.2714 \times 10^{-2}-1.24 \times 10^{-4} \hat{T}+2.281 \times 10^{-7} \hat{T}^{2}-1.474 \times 10^{-10} \hat{T}^{3} \\
\lambda & 0.443+1.9 \times 10^{-4} \hat{T}
\end{array}
$$

\section{Nitrogen}

$$
\begin{array}{ll}
\rho & p / 297 \hat{T} \\
c_{p} & 1060-0.21 \hat{T}+4.14 \times 10^{-4} \hat{T}^{2} \\
\mu & \left(2.38 \times 10^{-5} \sqrt{\frac{\hat{T}}{273.15}}\right) /(1+122 / \hat{T}) \\
\lambda & 2.5 \times 10^{-3} \sqrt{\hat{T}} /\left[1+(225 / \hat{T}) \times 10^{-12 / \hat{T}}\right] \\
\hline & \text { Steel A516gr70 } \\
\rho & 7858 \\
c_{p} & 483.9+4.4455 \times 10^{-2} T+7.231 \times 10^{-4} T^{2} \\
\lambda & 54.38-2.478 \times 10^{-2} T-1.071 \times 10^{-5} T^{2}
\end{array}
$$

Insulation Spintex342G-100

$$
\begin{array}{ll}
\rho & 100 \\
c_{p} & 1600 \\
\lambda & 2.966 \times 10^{-2}+1.255 \times 10^{-4} T+2.143 \times 10^{-7} T^{2}
\end{array}
$$

Table 3: Thermo-physical properties of the different material used in the simulation $(\hat{T}(K)$ and $T\left({ }^{\circ} \mathrm{C}\right)$, the rest of units as in the nomenclature). Molten salt taken from [42], steel A516gr70 adapted from ASME 31.1-2001 standard, Spintex342G-100 adapted from ISOVER data (www.isover.es) 
down of the tank, the same aspect ratios are maintained together with the real tank working conditions (i.e. initial and ambient temperatures), in order to preserve the similarity with the operation conditions as much as possible. This strategy is similar to that encountered in an scaled experimental set-ups (see for instance [43]) or in the numerical experiments of Yang and Garimella [15], where a tank with a simplified geometry is used for analysing the effects of the heat losses to the surroundings. The dimensions, non-dimensional numbers and mesh details considered in the present simulation are summarised in table 4. As reference, the same parameters but for the real tank are also shown in the table.

When considering LES simulations, one important aspect to be taken into consideration is to properly describe the turbulent boundary layers formed from the very beginning of the transient simulation. As there is no information of the boundary layer thickness for the case under study, two criteria are considered. The first is the one proposed by Grötzbach [44] for the Rayleigh-Bénard convection where the thermal boundary layer thickness is about $\delta_{\vartheta}=H / 2 N u$ (here the Nusselt number is estimated as $N u=0.124 R a^{0.309}$ [39]). The second criteria is the one proposed by Patterson and Imberger [45] for a boundary layer in a differential heated cavity $\delta_{\vartheta} \sim H / R a^{0.5}$. The results of both criteria are also given in table 4 and the most restrictive one is used. As for the grid resolution, according to Pope [46], the maximum dissipation occurs at a length scale of $24 \eta$. Thus for a well-solved LES grid sizes should be of that order of magnitude. Using Grötzbach [44] criteria as reference for evaluating the smallest scales of the flow, $\eta \sim \pi(\operatorname{Ra} \operatorname{PrNu})^{-0.25} H_{m s}$, the total number of control volumes $(N C V)$ have been estimated (see table 4). Since these constraints must be attained, special care is taken when constructing the computational meshes, considering that at least 3 
control volumes must be located within the boundary layer [44].

In order to assess the quality of the grid resolution, in a-posteriori analysis the ratio $(\gamma)$ between the resolved scales $(\Delta)$ to the smallest scales of the flow (i.e. the Kolmogorov scales, $\eta$ ) has been evaluated at each control volume of the domain [47]. The size of the resolved scales is determined by the mesh size (i.e. $\Delta=\Omega_{c v}^{1 / 3}$ ), whereas the Kolmogorov scales are defined as:

$$
\eta=\left(\frac{v^{3}}{\xi}\right)^{1 / 4}
$$

where the turbulent kinetic energy dissipation rate can be evaluated as [47]:

$$
\xi=2\left(\mathrm{v}+\mathrm{v}_{s g s}\right) \overline{\mathcal{S}_{i j}^{\prime}} \overline{S_{i j}^{\prime}}
$$

The ratio $\gamma$ gives not only an idea of the contribution of the LES model to the dissipation of the turbulent kinetic energy, but also is a measure of the mesh quality. A value of $\gamma \sim 1$ means that the mesh is capable of solving all the scales of the flow without SGS model. For the present computations this ratio has yielded values of the order of 5-7 in the zones near the core of the tank and reaches some peaks of $\gamma \sim 13$ near the outer zones of the tank, where due to the cylindrical extrusion of the mesh, grid sizes are the largest. According to Pope [46], the motions responsible for the dissipation of a scale larger than that of the Kolmogorov scale and in the range of $8<\gamma<60$, being the peak of the dissipation of the turbulent kinetic energy at about $\gamma \sim 24$. Thus, the ratios obtained conforms the capacity of the grid density used for solving most of the dissipation spectrum of the turbulent kinetic energy. This is also an indicative of the very good resolution achieved with the LES modelling.

Another issue to take into account when real working conditions are investigated, is the validity of the Boussinesq approximation (i.e. how density variations 


\begin{tabular}{ccccccccc} 
& $\mathrm{H}$ & $\mathrm{D}$ & $\mathrm{D} / \mathrm{H}$ & $\mathrm{Ra}$ & $\delta_{\vartheta}[44]$ & $\delta_{\vartheta}[45]$ & $N C V_{r} \times N C V_{z} \times N C V_{\theta}$ & $N C V\left(\times 10^{6}\right)$ \\
& 1 & 3.33 & 3.33 & $10^{10}$ & $3.16 \times 10^{-3}$ & $2.8 \times 10^{-3}$ & $260 \times 78 \times 64$ & 1.3 \\
\hline & 11.7 & 38.9 & 3.33 & $1.62 \times 10^{13}$ & $5.8 \times 10^{-3}$ & $1.7 \times 10^{-3}$ & $1825 \times 914 \times 192$ & 320 \\
\hline
\end{tabular}

Table 4: LES mesh detail for the CFD\&HT molten salt object 
with temperature are approximated). According to Gray and Giorgini [48], the use of this approximation can be considered valid for variations in density up to a $10 \%$ with respect to the mean value. In this work, variations in density due to temperature differences have been no larger than $0.4 \%$. Thus, Boussinesq hypothesis can be considered valid during the whole simulation.

Simulations have been carried out for the first $12 \mathrm{~h}$ of the cooling-down process. It has been observed that after a strong initial transient due to the onset of the turbulent natural convection inside the tank, the flow reaches a quasi-steady period. During this quasi-steady process the fluid cool down occurs at an almost constant ratio, as it is depicted in figure 7.

Figure 8 depicts the transient evolution of the molten salt within the container during the first 5 hours of the transient cooling process. At the beginning of the cooling-down process a turbulent boundary layer rapidly develops at the vertical walls of the storage. The cold fluid descends close to the vertical walls and impinges at the bottom of the tank. Due to the temperature gradient, the main activity is concentrated near the walls in an outer ring which goes approximately from $r=2 D / 3$ to $r=D / 2$. Once the cold fluid reaches the bottom of the tank it advances towards the bottom centre. As a consequence of the low flow activity in that area, close to the bottom centre of the container, the boundary layer formed in the central zone is thicker than that formed in the outer regions. Thus, in the bottom of the tank differences in temperatures can also be observed. A small cold region is also formed in the bottom corner, due to a small recirculation caused by the turbulent impingement of the vertical boundary layer. In this recirculation zone the temperature of the salt can remain at about $1.5-2.5^{\circ} \mathrm{C}$ below the temperature of the core. Thus, these zones might be the focus of the initial freezing 
of the salt if the cooling-down process is extended until the salt freezing point is reached $\left(\sim 240^{\circ} \mathrm{C}\right)$.

Due to the heat losses through the free-surface, thermal plumes are also formed at the top of the tank. These downward plumes of colder fluid descend continuously and penetrate the hotter core. The flow displaced by these plumes eventually turns upwards establishing up and down circulation motions. As a result, turbulent mixing occurs throughout the whole tank with plumes of cold fluid displacing hot layers and colder boundary layers descending through the vertical walls. To have an idea of this turbulent mixing process inside the tank, in figure 9 streamlines of one of these instants are shown. One can have a rough idea of the significant intensity of the turbulent flow when observing such image. Vertical streamlines accumulate throughout the fluid giving the appearance of the currents flowing up and down in the container, while at the same time random vortices are formed and transported by the convective movement.

In order to have a more complete picture about the transient evolution of the temperature and its distribution within the tank, some instantaneous plots at different locations and times are depicted in figures 10 to 12 . In figure 10 , the temperature distribution along the vertical axis at different instants of the cooling process is given. As can be observed, most of the tank is at the same temperature and, temperature drops are only observed at small region near the bottom of the tank and at the top free surface, where losses due to convection and radiation produce the emission of thermal plumes. A closer inspection to the temperature distribution at different vertical locations is shown in figure 11. These figures correspond at different instants of the cooling process. As can be seen, due to the strong turbulent mixing the core of the tank is at almost the same temperature and with 
larger temperature differences near the top and bottom of the tank. A similar distribution is obtained if temperatures are plotted at the mid-height of the tank (see figure 12). In this case, a thin boundary layer is formed close to the vertical walls (see figure 12 insight) with a rapid increase in temperature when moving away from the walls.

It should be pointed out that after the initial transient, the average Nusselt number evaluated at the vertical wall seems to fluctuate around a constant value, $N u=324$ approximately. Here, the Nusselt number is defined as,

$$
N u=\frac{\dot{q}_{v w} H_{m s}}{\lambda\left(\bar{T}_{v w}-\bar{T}_{m s}\right)}
$$

where $\bar{T}_{v w}$ and $\bar{T}_{m s}$ are the instantaneous mean temperatures of the vertical wall and the molten salt fluid, respectively. Another striking fact is that the temperature difference between the wall and the molten salt remaines almost constant on average, around a value $\bar{T}_{v w}-\bar{T}_{m s}=0.64^{\circ} \mathrm{C}$, during the whole simulated process. In figure 13, the transient evolution of these average temperatures and their difference are plotted. This temperature difference is slightly lower than the one reported by Schulte-Fischedick et al. [18] in their simulations, which was of about $1^{\circ} \mathrm{C}$. Discrepancies between these values might be due to differences in the geometry and boundary conditions, specially due to the scaling in the tank dimensions. Another possible focus of discrepancy between both results might be the level of turbulence modelling used. In their work a RANS model is used, whereas in the present work calculations are performed with LES. As previously pointed out, RANS models might fail in predict transient flows. However, bearing in mind the possible causes of discrepancies, differences are not large enough to distinguish between sources of errors. In this case, both computations point out towards the 
formation of a thin boundary layer in the vertical walls. Furthermore, from the present results it is shown that, with the exception of localised zones, almost the whole core remains at the same temperature due to the turbulent mixing. This in an important feature to consider if studies with simplified models are to be carried out. If this is the case, a good modelisation of the heat transfer coefficients at the walls through systematic studies might help to fine tuning such simplified models.

\section{Conclusions}

A modular object-oriented methodology has been used for the transient thermal and fluid dynamic simulation of molten salt storage tanks for CSP plants. This methodology takes advantage of the existing NEST platform [19] and the parallel CFD software TermoFluids [21] to develop a versatile methodology which implements different levels of modelling for the components of a storage tank. These elements interact among each other by means of the boundary conditions, while the global algorithm implemented in NEST platform allows their coupled resolution at each time step. One of the advantages of this kind of modelling is that each element is programmed (and validated) once, but can be used several times and in different ways (e.g. the wall model can be set-up as an insulation vertical wall or as part of the foundation). Thus, different configurations can be made by just changing the way each object is linked.

The possibilities of the proposed methodology have been presented by means of the analysis of different situations. First, thermal losses for the Andasol twotank system have been evaluated using global and detailed models for the molten salt and solid elements respectively, but considering the real geometry in detail. After that, the potential of the methodology has been challenged by using 
a CFD\&HT model including LES modeling for the molten salt media. In order to gain confidence in the LES model used, the turbulent Rayleigh-Benard convection has been solved. This case involves similar turbulent natural convection phenomena present in molten salt tanks. In the analysis, the LES results have been compared with experimental and direct numerical results showing a very good accuracy.

After numerical validation, the cooling-down process of a molten salt has been studied. A-posteriori analysis of the grid resolution used in the present case has shown the high quality of the mesh used and the capability of the LES model used in solving most of the dissipation spectrum of the turbulent kinetic energy. The transient process has shown that as the salt cools-down, and after an initial transient, the process occurs in a quasi-steady state in which heat is exchanged at almost constant rate. The turbulent modelling has also shown that regarding the cold boundary layer formed in the tank walls, the turbulent natural convection produces a strong mixing of the cold fluid at the boundaries with the hotter core. As a result, only a small layer of colder fluid at the bottom centre and at the bottom corners of the tank remains at a lower temperature, and thus special care should be taken as it might be a possible focus of salt freezing if the process is extended until the salt freezing point.

Finally, it has to be pointed out that CFD\&HT simulations using LES modelling allow a more realistic picture of the phenomena taking place inside the tank. By means of these simulations it will be possible to develop correlations for the local heat transfer coefficients at the tank walls, which will improve the predictions when global models for the complete tank are used for predicting long-term behaviour. 


\section{Acknowledgements}

This work has been by financially supported by the Ministerio de Economía y Competitividad, Secretaría de Estado de Investigación, Desarrollo e Innovación, Spain (ref. ENE2010-17801), by the EIT through the KIC InnoEnergy TESCONSOL project (ref. 20_2011_IP16) and by the Collaboration Project between Universitat Politècnica de Catalunya and Termo Fluids S.L.

[1] Ortega JI, Burgaleta JI, Tellez FM. Central Receiver System Solar Power Plant Using Molten Salt as Heat Transfer Fluid. Journal of Solar Energy Engineering 2008;130(2):1-6. doi:10.1115/1.2807210.

[2] Relloso S, Lata J. Molten salt thermal storage: a proven solution to increase plant dispatchability. Experience in Gemasolar Tower plant. In: Proceeedings of SolarPaces. 2011, p. 1-6.

[3] Dominguez R, Baringo L, Conejo AJ. Optimal offering strategy for a concentrating solar power plant. Applied Energy 2012;98:316-25. doi: 10.1016/j.apenergy.2012.03.043.

[4] Ghaddar N, Al-Marafie A, Al-Kandari A. Numerical simulation of stratification behaviour in thermal storage tanks. Applied Energy 1989;32(3):225 -39. doi:10.1016/0306-2619(89)90031-7.

[5] Zurigat Y, Maloney K, Ghajar A. A comparison study of one-dimensional models for stratified thermal storage tanks. Journal of Solar Energy Engineering 1988;111:204-10.

[6] Alizadeh S. An experimental and numerical study of thermal stratification in a horizontal cylindrical solar storage tank. Solar Energy 1999;66(6):409-21. 
[7] Ghajar A, Y.H. Z. Numerical study of the effect of inlet geometry on stratification in thermal energy storage. Numerical Heat Transfer, Part A 1991;19:65-83.

[8] Kleinbach E, Beckman W, Klein S. Performance study of one-dimensional models for stratified thermal storage tanks. Solar Energy 1993;50(2):15566.

[9] Gabbrielli R, Zamparelli C. Optimal Design of a Molten Salt Thermal Storage Tank for Parabolic Trough Solar Power Plants. Journal of Solar Energy Engineering 2009;131(4). doi:10.1115/1.3197585.

[10] Cònsul R, Rodríguez I, Pérez-Segarra C, Soria M. Virtual prototyping of storage tanks by means of three-dimensional CFD and heat transfer simulations. Solar Energy 2004;77(2):179-91.

[11] Papanicolaou E, Belessiotis V. Transient natural convection in a cylindrical enclosure at high Rayleigh numbers. International Journal of Heat and Mass Transfer 2002;45:1425-44.

[12] Oliveski RDC, Krezinger A, Vielmo H. Cooling of cylindrical vertical tanks submitted to natural internal convection. International Journal of Heat and Mass Transfer 2003;46:2015-26.

[13] Rodríguez I, Castro J, Pérez-Segarra C, Oliva A. Unsteady numerical simulation of the cooling process of vertical storage tanks under laminar natural convection. International Journal of Thermal Sciences 2009;48(4):708-21.

[14] Rodríguez I, Perez-Segarra CD, Oliva A, Jaramillo JE. Numerical Study of the Transient Cooling Process of Water Storage Tanks under Heat 
Losses to the Environment. Numerical Heat Transfer, Part A: Applications 2009;55(12):1051-74. doi:10.1080/10407780903014418.

[15] Yang Z, Garimella SV. Molten-salt thermal energy storage in thermoclines under different environmental boundary conditions. Applied Energy 2010;87(11):3322-9. doi:10.1016/j.apenergy.2010.04.024.

[16] Flueckiger S, Yang Z, Garimella SV. An integrated thermal and mechanical investigation of molten-salt thermocline energy storage. Applied Energy 2011;88(6):2098-105. doi:10.1016/j.apenergy.2010.12.031.

[17] Xu C, Wang Z, He Y, Li X, Bai F. Sensitivity analysis of the numerical study on the thermal performance of a packed-bed molten salt thermocline thermal storage system. Applied Energy 2012;92:65-75. doi: 10.1016/j.apenergy.2011.11.002.

[18] Schulte-Fischedick J, Tamme R, Herrmann U. CFD Analysis of the Cool Down Behaviour of Molten Salt Thermal Storage Systems. In: ES2008, Energy Sustainability. 2008, p. 10-4.

[19] Damle R, Lehmkuhl O, Colomer G, Rodríguez I. Energy simulation of buildings with a modular object-oriented tool. In: ISES World Conference. 2011, p. $1-8$.

[20] Incropera F, DeWitt D. Fundamentals of Heat and Mass Transfer. John Wiley and Sons Inc.; 5th ed.; 2002.

[21] Lehmkuhl O, Perez-Segarra CD, Borrell R, Soria M, Oliva A. TERMOFLUIDS: A new Parallel unstructured CFD code for the simulation of turbulent 
industrial problems on low cost PC Cluster. In: Tuncer I, Gülcat U, Emerson D, Matsuno K, editors. Proceedings of the 2005 Parallel Computational Fluid Dynamics Conference; vol. 67 of Series: Lecture Notes in Computational Science and Engineering. Springer; 2007, p. 275-82.

[22] Sagaut P, Germano M. Large Eddy Simulation for Incompressible Flows. Springer-Berlag; 2001.

[23] Germano M, Piomelli U, Moin P, Cabot W. A Dynamic Subgrid-Scale Eddy Viscosity Model. Physics of Fluids A 1991;7(3):1760-5. doi: $10.1063 / 1.857955$.

[24] Nicoud F, Ducros F. Subgrid-scale stress modelling based on the square of the velocity gradient tensor. Flow, Turbulence and Combustion 1999;62:183-200. doi:10.1023/A:1009995426001.

[25] Hughes T, Mazzei L, Jansen K. Large eddy simulation and the variational multiscale method. Computing and Visualization in Science 2000;3:47-59. doi:10.1007/s007910050051.

[26] Verstappen R. When Does Eddy Viscosity Damp Subfilter Scales Sufficiently? Journal of Scientific Computing 2011;49(1):94-110. doi: 10.1007/s10915-011-9504-4.

[27] Verstappen RWCP, Veldman AEP. Symmetry-Preserving Discretization of Turbulent Flow. Journal of Computational Physics 2003;187:343-68. doi: 10.1016/S0021-9991(03)00126-8. 
[28] Le H, Moin P. An improvement of fractional step methods for the incompressible navier-stokes equations. Journal of Computational Physics 1991;92(2):369 -79. doi:10.1016/0021-9991(91)90215-7.

[29] Kim D, Choi H. A second-order time-accurate finite volume method for unsteady incompressible flow on hybrid unstructured grids. Journal of Computational Physics 2000;162(2):411 -28. doi:10.1006/jcph.2000.6546.

[30] Fishpool G, Leschziner M. Stability bounds for explicit fractional-step schemes for the Navier-Stokes equations at high Reynolds number. Computers and Fluids 2009;38:1289-98.

[31] Trias F, Lehmkuhl O. A self-adaptive strategy for the time integration of navier-stokes equations. Numerical Heat Transfer Part B 2011;60(2):11634. doi:10.1080/10407790.2011.594398.

[32] Trias F, Gorobets A, Soria M, Oliva A. Direct numerical simulation of a differentially heated cavity of aspect ratio 4 with rayleigh numbers up to $10^{11}$. part $\mathrm{i}$ : Numerical methods and time-averaged flow. International Journal of Heat and Mass Transfer 2010;53(4):665 -73. doi: 10.1016/j.ijheatmasstransfer.2009.10.026.

[33] Rodríguez I, Lehmkuhl O, Borrell R, Oliva A. Flow dynamics in the wake of a sphere at sub-critical Reynolds numbers. Computers \& Fluids 2012; doi: 10.1016/j.compfluid.2012.03.009.

[34] Jaramillo J, Trias F, Gorobets A, Pérez-Segarra C, Oliva A. Dns and rans modelling of a turbulent plane impinging jet. Interna- 
tional Journal of Heat and Mass Transfer 2012;55(4):789 - 801. doi: 10.1016/j.ijheatmasstransfer.2011.10.031.

[35] Rodríguez I, Borrell R, Lehmkuhl O, Pérez-Segarra C, Oliva A. Direct Numerical Simulation of the Flow Over a Sphere at $\mathrm{Re}=3700$. Journal of Fluids Mechanics 2011;679:263-87. doi:10.1017/jfm.2011.136.

[36] Capdevila R, Lehmkuhl O, Trias F, Pérez-Segarra C, Colomer G. Turbulent natural convection in a differentially heated cavity of aspect ratio 5 filled with non-participating and participating grey media. In: Journal of Physics: Conference Series.; vol. 318. 2011,doi:10.1088/1742-6596/318/4/042048.

[37] Lehmkuhl O, Borrell R, Rodríguez I, Pérez-Segarra C, Oliva A. Assessment of the Symmetry-Preserving Regularization model on complex flows using unstructured grids. Computers \& Fluids 2012;60:108-16.

[38] Rodriguez I, Lehmkuhl O, Borrell R, Perez-Segarra CD. On DNS and LES of natural convection of wall-confined flows: Rayleigh-Benard convection. In: Kuerten, Hans , Geurts B, Armenio V, Fröhlich J, editors. Direct and large-eddy simulation VIII. Springer; 2011, p. 389-94. doi:10.1007/978-94007-2482-2.

[39] Niemela J, Skrbek L, Sreenivasan K, Donnelly R. Turbulent convection at very high Rayleigh numbers. Nature 2000;404.

[40] Ficha Técnica. Monesa I\&C; 2007.

[41] Kelly B, Barth D, Brosseau D, Konig S, Fabrizi F. Nitrate and nitrate/nitrate salt heat transport fluids. In: Parabolic Trough Technology Workshop. Golden, Colorado; 2007, p. 1-6. 
[42] Ferri R, Cammi a, Mazzei D. Molten salt mixture properties in RELAP5 code for thermodynamic solar applications. International Journal of Thermal Sciences 2008;47(12):1676-87. doi:10.1016/j.ijthermalsci.2008.01.007.

[43] Pacheco JE, Showalter SK, Kolb WJ. Development of a Molten-Salt Thermocline Thermal Storage System for Parabolic Trough Plants. Journal of Solar Energy Engineering 2002;124(2):153-9. doi:10.1115/1.1464123.

[44] Grötzbach G. Spatial resolution requirements for direct numerical simulation of the Rayleigh-Bénard convection. Journal of computational physics 1983;49:241-64.

[45] Patterson J, Imberger J. Unsteady natural convection in a rectangular cavity. Journal of Fluids Mechanics 1980;100:65-86.

[46] Pope S. Turbulent Flows. Cambridge University Press; 2000.

[47] Fröhlich J, Mellen CP, Rodi W, Temmerman L, Leschziner Ma. Highly resolved large-eddy simulation of separated flow in a channel with streamwise periodic constrictions. Journal of Fluid Mechanics 2005;526:19-66. doi:10.1017/S0022112004002812.

[48] Gray D, Giorgini A. The validity of the Boussinesq approximation for liquids and gases. International Journal of Heat and Mass Transfer 1976;19:545-51. 


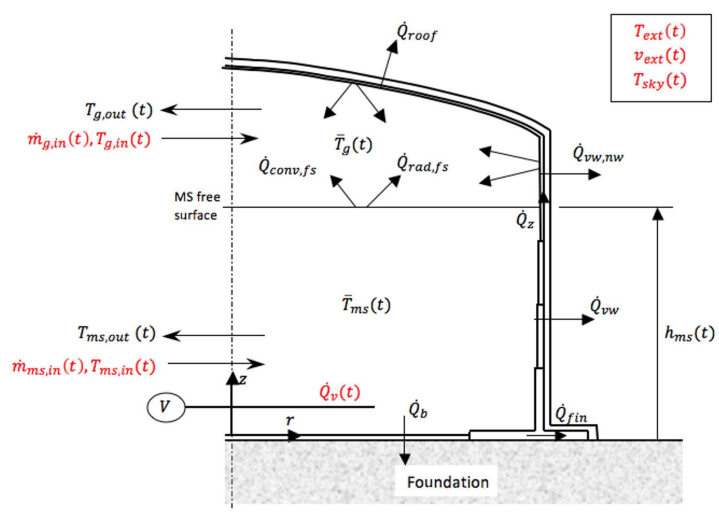

Figure 1: Boundary conditions of the different elements of the storage tank

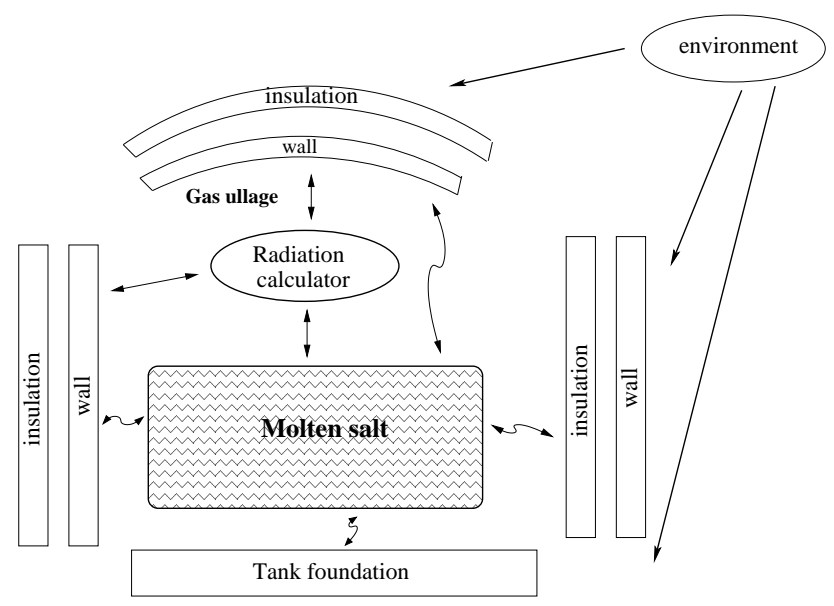

Figure 2: Schematic of the modular storage tank methodology 


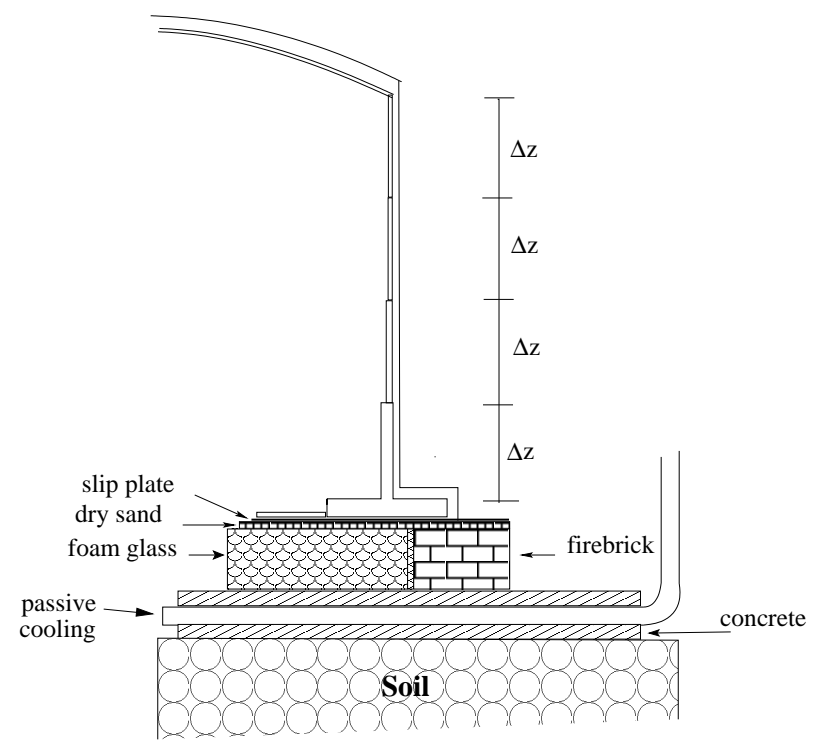

Figure 3: Detail of the different layers which compose the contained. Adapted from [41]

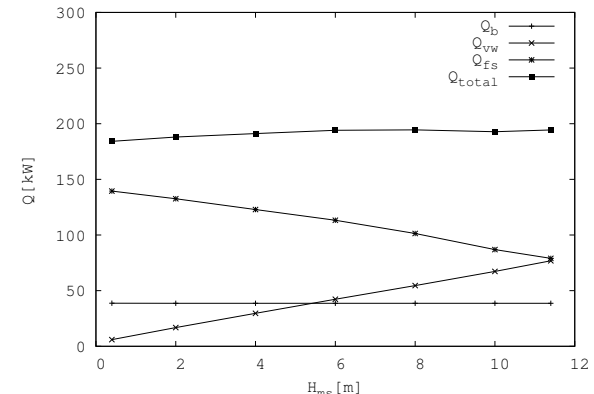

(a)

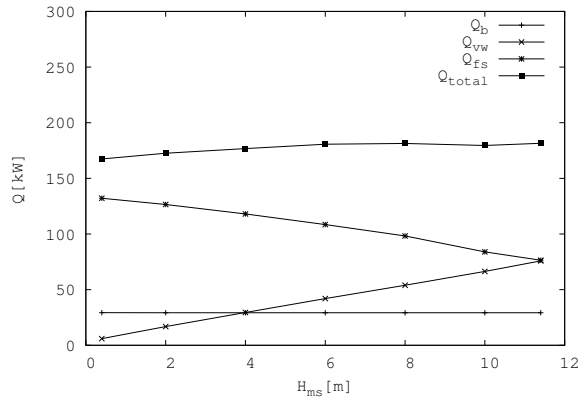

(b)

Figure 4: Heat losses through the different elements of the tank as a function of the molten salt height. (a) Hot tank, (b) cold tank 


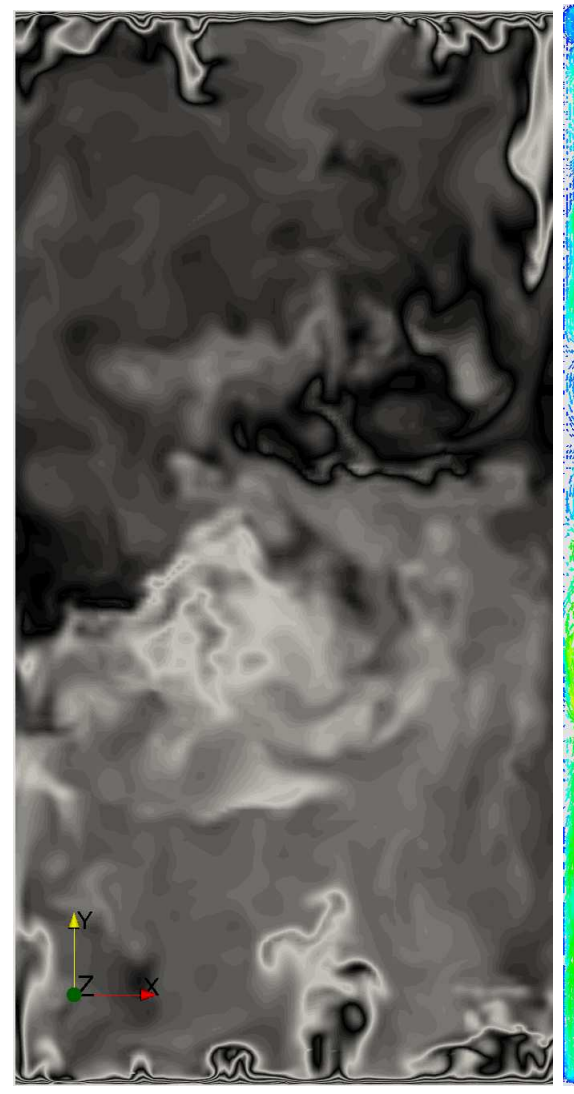

(a)

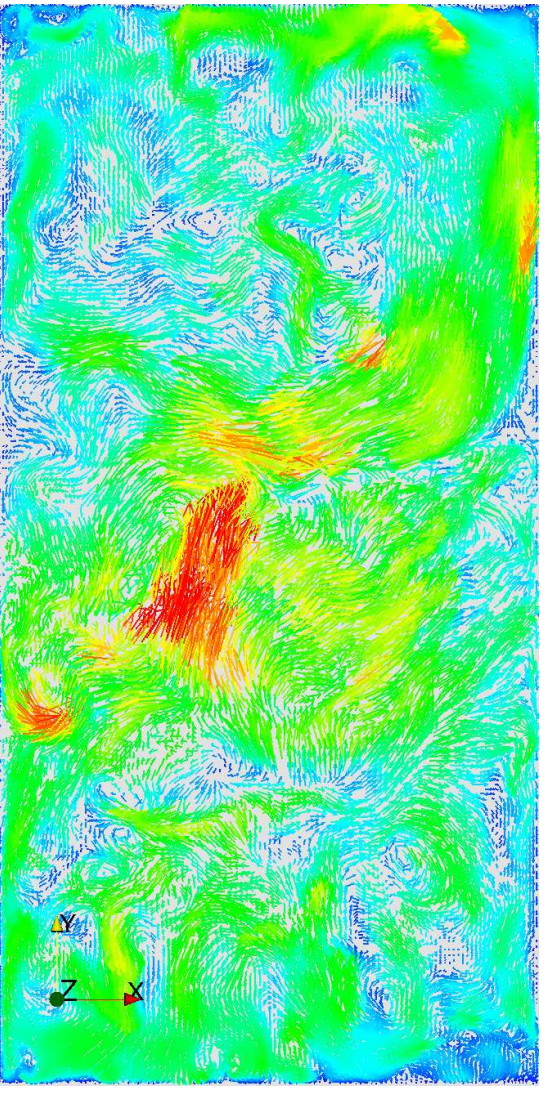

(b)

Figure 5: Rayleigh-Benard flow configuration. (a) Shadowgraph image of the thermal plumes. (b) Velocity vectors. 


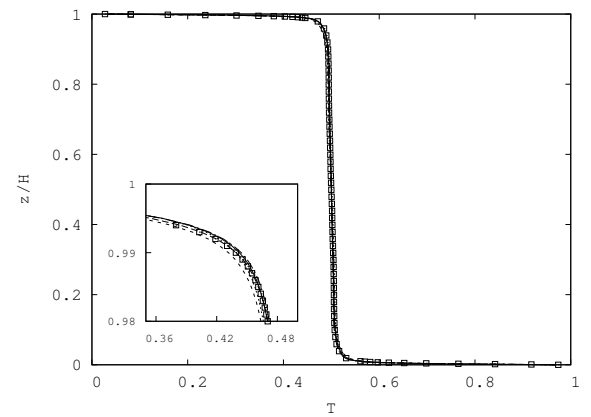

(a)

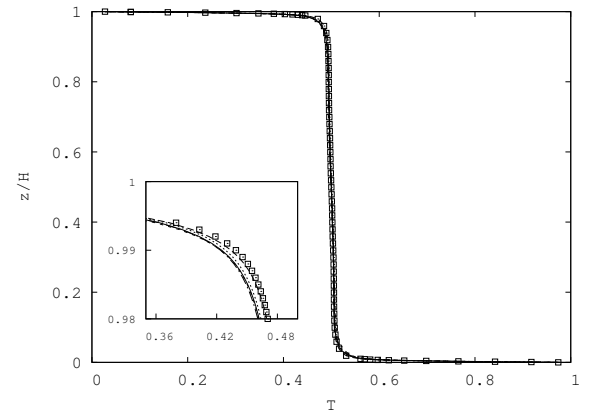

(c)

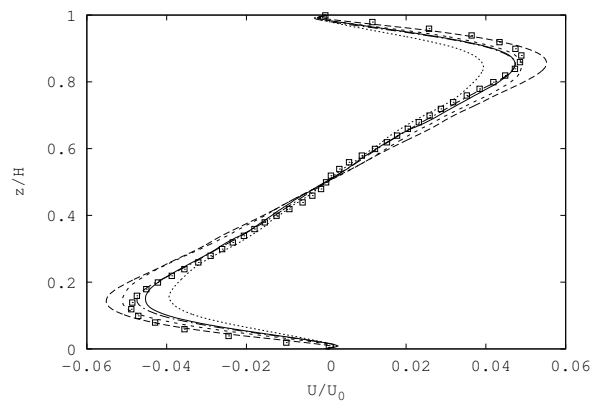

(b)

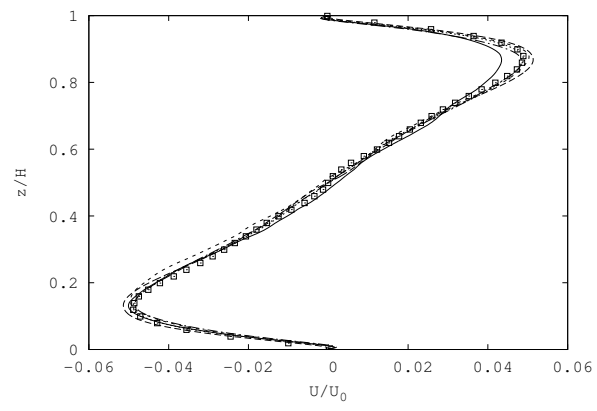

(d)

Figure 6: Comparison of vertical profiles at the axis of the cylinder for the meshes $\mathrm{m} 1$ and $\mathrm{m} 3$ (left) temperature; (right) axial velocity (a,b) $m 1$; (c,d) $m 3$. Z DNS; long-dashed line DEV; dashed line QR; dash-dotted line WALE; solid line VMS-WALE; dotted line no-model. 


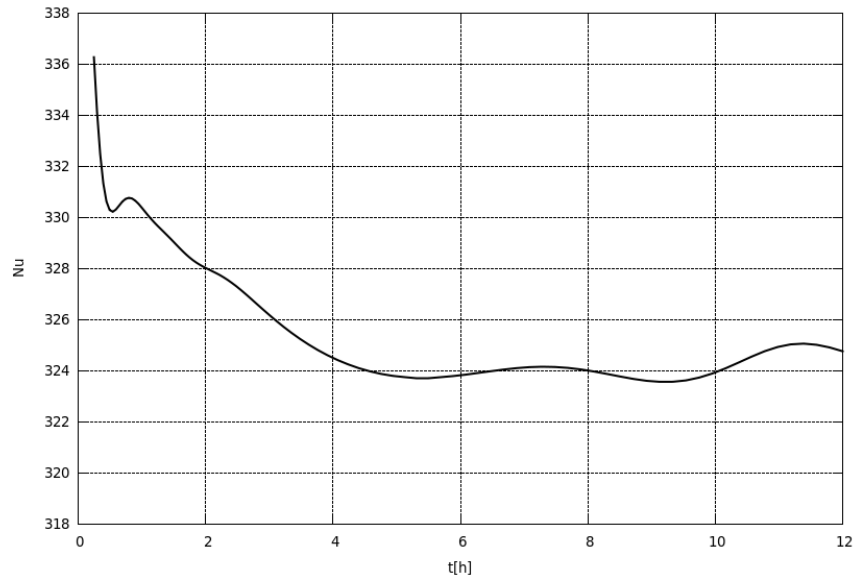

Figure 7: Transient average Nusselt number at the vertical wall 


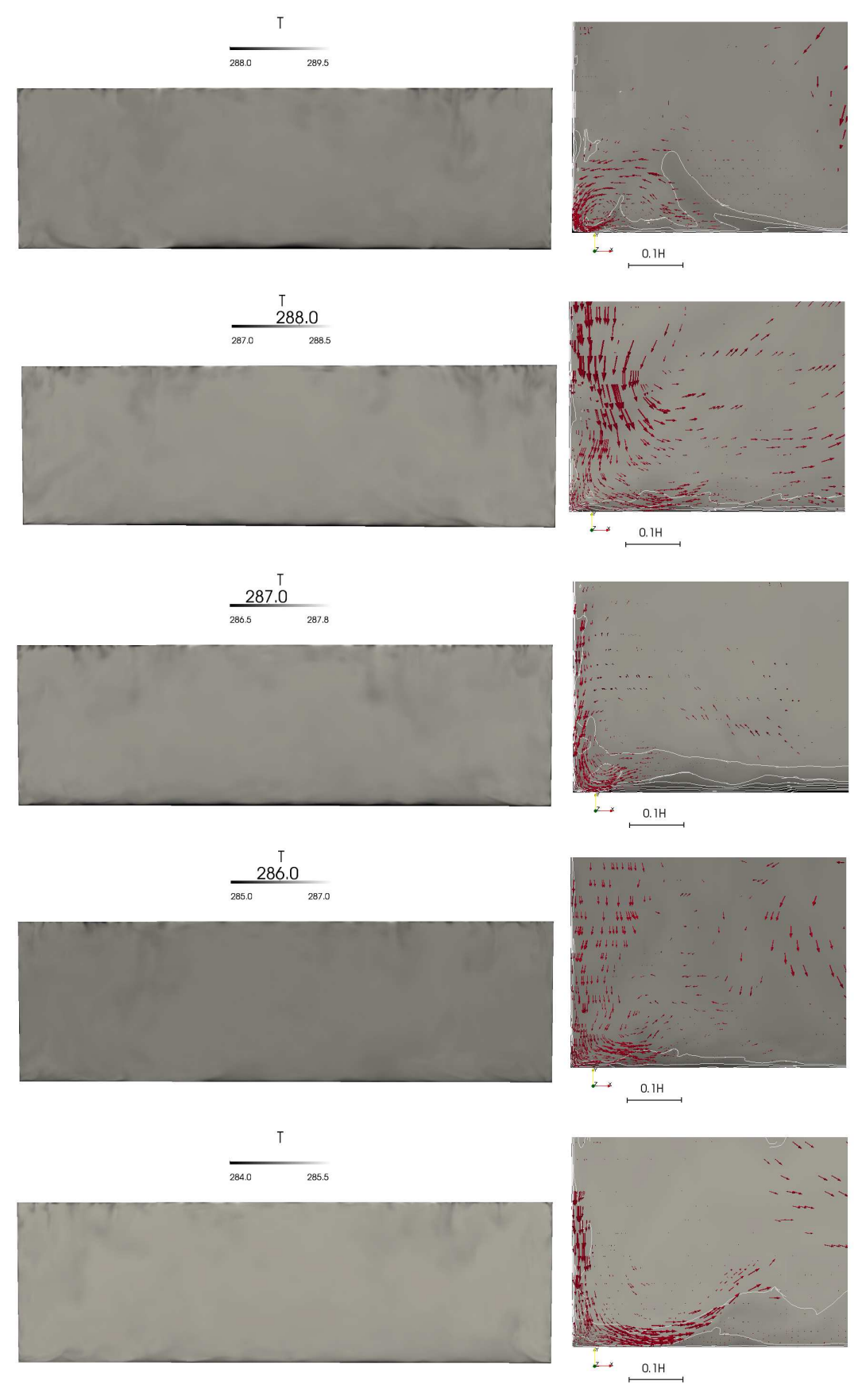

Figure 8: Transient evolution of the molten salt inside the storage. Each snapshot is taken every 3600 s (from top to bottom). A close-up of the bottom corner is also shown (right). 


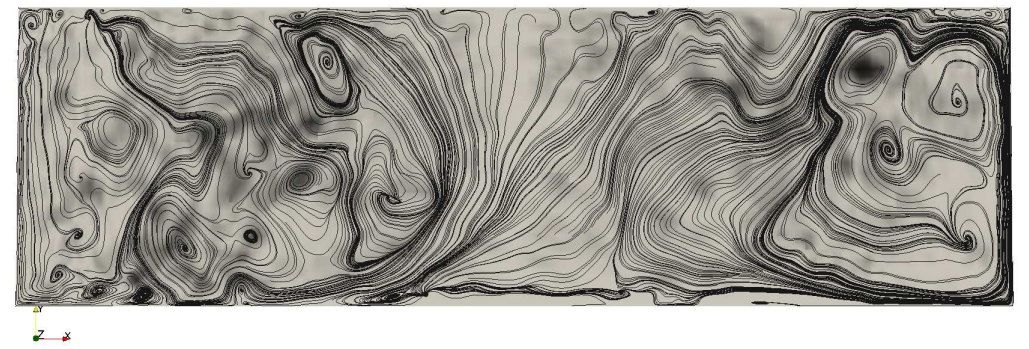

Figure 9: Instantaneous streamlines an arbitrary vertical planes of the tank.
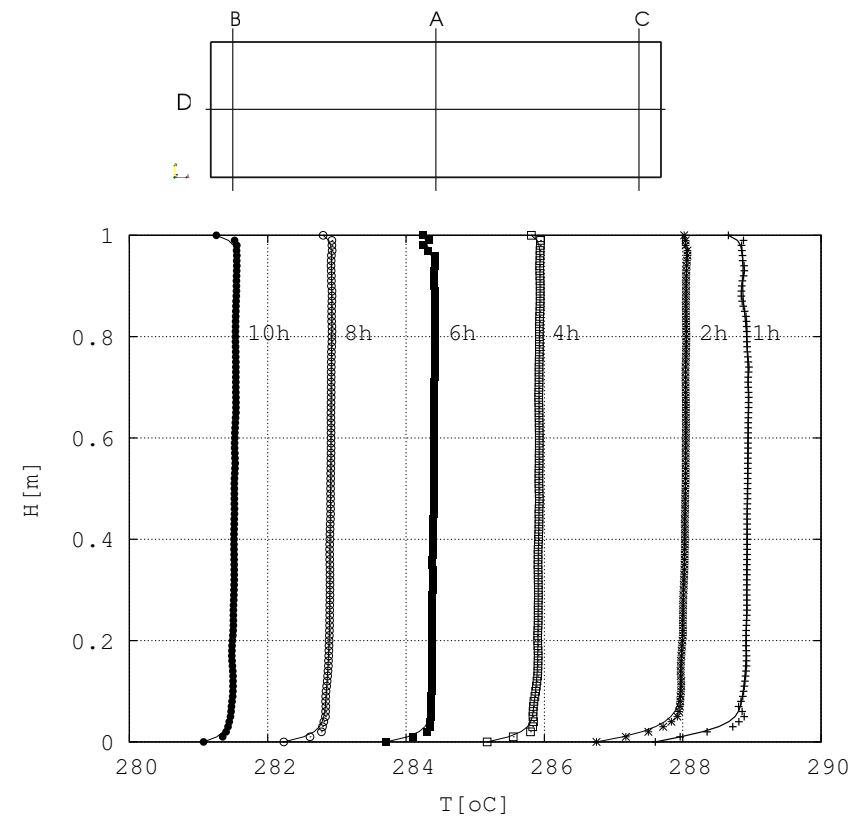

Figure 10: Evolution of the temperature profile along the axis (A) during the cooling process 


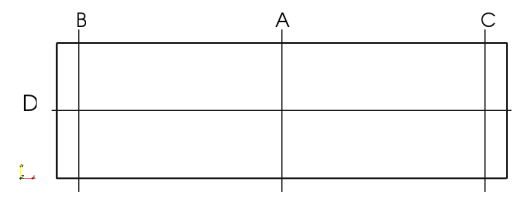

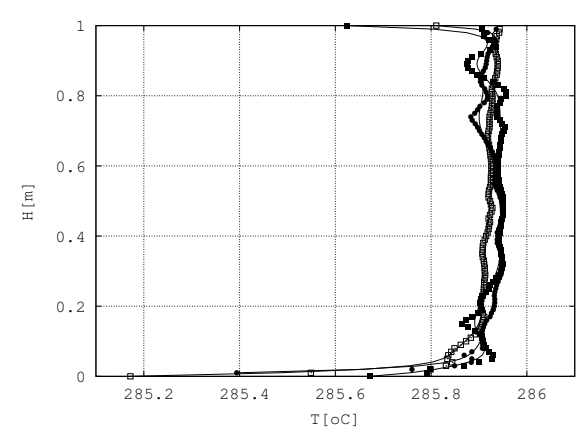

(a)

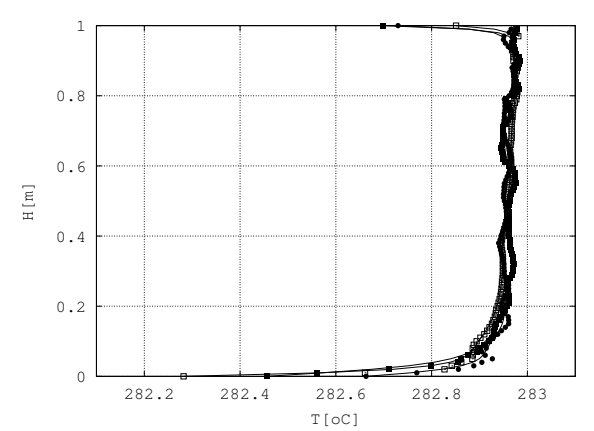

(b)

Figure 11: Instantaneous temperature profile at different vertical locations of the tank (lines A,B,C). (a) after 4 hours of the cooling process; (b) after 8 hours of the cooling process 


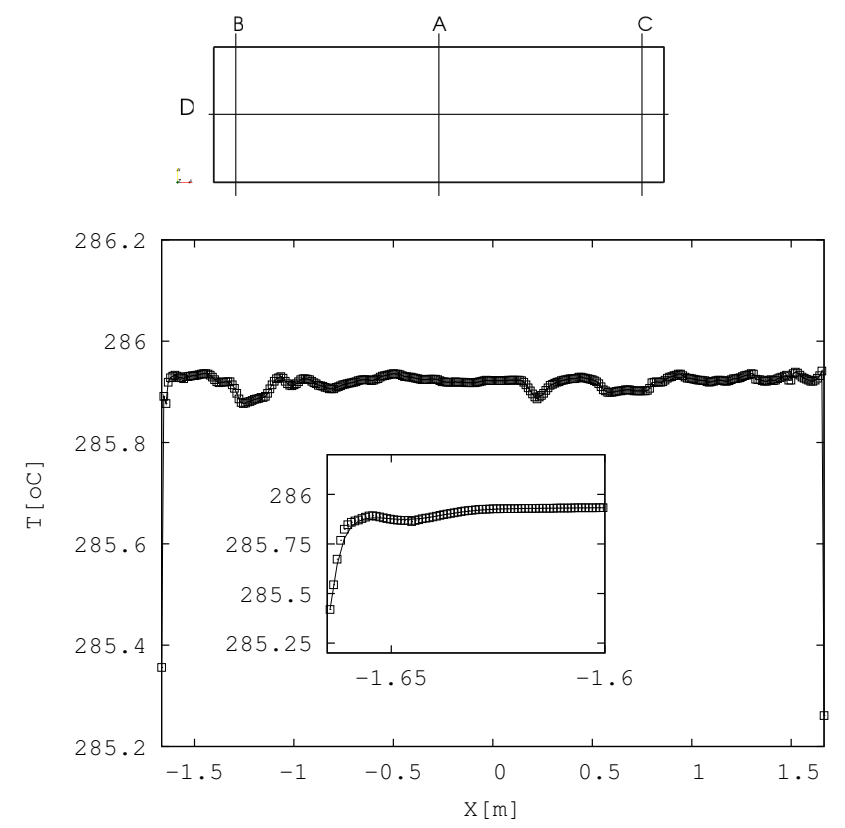

Figure 12: Instantaneous temperature profile at the mid-heigh of the tank (line D) after 4 hours of the cooling process

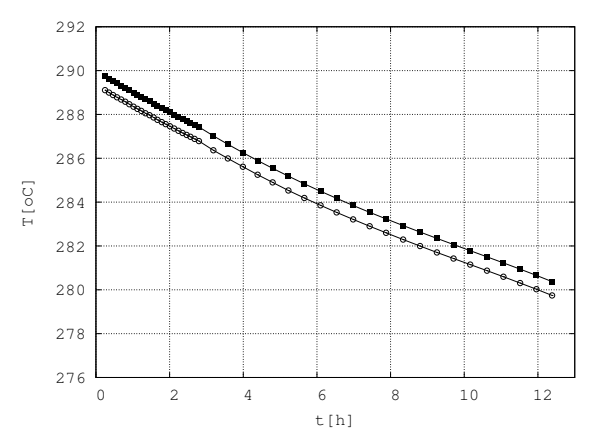

(a)

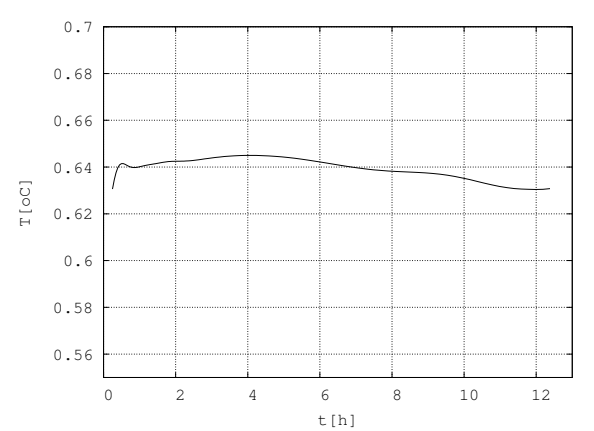

(b)

Figure 13: (a) Evolution along the time of the average temperature of the molten salt (solid squares) and average wall temperature (circles) (b) Temperature difference between the wall and the molten salt. 


\section{Highlights}

A modular object oriented methodology is proposed for the transient simulation of molten-salt tanks.

At implements different levels of modelling for the components of the storage.

Each element is programmed once but can be used several times and in different ways.

The cool-down process of the salt show differences in salt temperature up to $2.5^{\circ} \mathrm{C}$.

The use of CFD\&HT would improve the long term prediction of these systems.

Turbulence is modelled using advanced LES methodologies. 